\title{
Theory of mind and its neural mechanisms: A case study of Kurdish-Persian congenitally blind children in Ilam city
}

\author{
Shahla Raghibdoust ${ }^{1 *}$, Elham Sobati ${ }^{2}$, Vida Shaghaghi ${ }^{1}$
}

1. Department of General Linguistics, Faculty of Literature and Foreign Languages, Allameh Tabataba'i University, Tehran, Iran

2. Department of General Linguistics, PhD Student of General Linguistics, Allameh Tabataba'i University, Tehran, Iran

*Corresponding author:Tel: +98 9124951759; Fax: +98 88690020

Address: Department of General Linguistics, Faculty of Literature and Foreign Languages, Allameh

Tabatabaei University, Tehran, Iran

E-mail: neishabour@hotmail.com

Received: 2017/09/16 revised: 2017/10/20 accepted: 2017/11/17

\begin{abstract}
Introduction: Theory of mind is one of the most important aspects of cognitive faculty. The theory of mind is impaired in individuals who suffer from mental disorders like autistic children. The 'autistic-like' behaviors also have been reported in the congenitally blind children. This study was conducted to examine the presence or absence of theory of mind and its function in congenitally blind children.

Materials and methods: A number of 20 individuals containing 10 bilingual congenitally blind children from Baghcheban elementary school of Ilam city as a case group and 10 sighted ones as a control group were selected. Three kinds of false belief cognitive tests appropriate for the congenitally blind children were designed. The collected data were analyzed using one sample Kolmogorov-Smirnov test, independent t-test along with Levenn test and one-way and two-way Analysis of Variance.

Results: Considering the performance of congenitally blind children in false belief tasks, the blindness just had effect on the story narration task $(\mathrm{P}<0.05)$, while it did not have any effect on the two other tasks. The same performance of the male and female subjects indicated that gender did not have any impact on the development of the theory of mind $(\mathrm{P}>0.05)$.

Conclusion: The findings showed only the story narration task was affected by blindness, because this task was more dependent on visual sense. Therefore, blindness results in delay in evolution of theory of mind. To fix this delay, the congenitally blind children should be exposed to further tactile and olfactory inputs.
\end{abstract}

Keywords: Congenitally blind, Theory of mind, False belief task, Mirror neurons, Ilam

\section{Introduction}

Social interaction is one of the most important differences between human and animal. Presence of this feature in individuals requires one knows how others think and how they feel. This mindreading capacity is known as "theory of mind" $(1,2)$. Premack and Woodruff (2) for the first time defined the theory of mind in "Does the chimpanzee have a theory of mind"?, As the ability to interpret others' behaviors in terms of mental states such as ideas, conceptions, passions, wills, tendencies, knowledge and to understand that these mental states in

Copyright (C) 2018 Journal of Basic Research in Medical Science. This is an open access article distributed under the terms of the Creative Commons Attribution 4.0 International License (https://creativecommons.org/licenses/by-nc/4.0/) which permits copy and redistribute the material, in any medium or format, provided the original work is properly cited. 
other individuals are distinct from one's own. Neuroscientists identified some brain regions associated with the theory of mind by the neuroimaging study of human and animal's brain.

The specific types of cells termed as 'mirror neurons' have been observed in the temporal lobes of non-human primates. These neurons activate during the certain hand or mouth action or the mere observation of the creature's imitation of our behavior. The greater density of these neurons has been discovered in the ventral premotor cortex of macaque monkeys (area F5), which this area was parallel with the Broca area in humans $(3,4)$. In the human brain, The STS (Superior Temporal Sulcus) cells activate when people observe that others imitate their actions which it indicates the presence of mirror neuron in this area (5). The mirror neurons give us information about others' wills and feeling. Therefore, it considered to be the basic neural system from which the theory of mind developed. People will be able to imagine themselves in the position of others and understand them and their conditions through the mirror neurons. fMRI studies of the human brain indicated that also the observation of a mimed action activates the mirror neurons (4). From an evolutionary viewpoint, observing the others imitation of our behaviors is the basis of the theory of mind evolution. The brain areas that engage in the theory of mind faculty are a neural network including the frontal lobes, the Superior Temporal Sulcus (STS), the Anterior Cingulate Cortex or ACC (the information of motor cortex, the spinal cord, prefrontal cortex, thalamus, and brainstem nuclei are received by the ACC and it placed in the Brodmann areas 24, 25 and 33), and the inferior parietal cortex (6).

Many separate brain circuits are responsible for the process of social understanding. Three of which particularly the theory of mind network (the medial Prefrontal Cortex (mPFC), TemporoParietal Junction (TPJ), temporal poles and precuneus $(7,8)$ and the mirror neuron system (Inferior Frontal Gyrus (IFG) and Inferior Parietal Lobe (IPL)) (12, 9). However, the neural regions of the theory of mind are not limited to the mentioned regions (10).

The ontogeny of theory of mind in children: The argument about ToM can be traced back in the philosophical debate of Descartes' Second Meditation, which paves the way for the evolution of the theory of mind. Some scientists like Carruthers (11), Moore (12), Flavell and Miller (13) suggested divergent theories about the children's development of the theory of mind. The three most important of these theories are Theory-Theory (TT), Modular Theory, and Simulation Theory which briefly review in the following:

Theory-Theory (TT): In theory-theory, it is assumed that the theory of mind is innate. This theory is considered as a scientific or in the psychological term as an argument about the minds of others. It evolves spontaneously and intrinsically, while social interactions also affect its evolutionary process (11). According to this theory, a child's thinking mature through scientific discovery. Therefore, individual's experience plays a vital role in the evolution of the theory of mind faculty (14).

Modular Theory: This theory suggests that there is a separate area for the theory of mind in the brain that only deals with social information processing and is independent of the other cognitive abilities (15). Also, this theory assumes the theory of mind as an innate faculty (16). In other words, the development of the theory of mind mainly depends on neurological maturation (17).

Simulation Theory: The simulation theory suggests that children are aware of their mental states intrinsically and through the capability of imagery "see through someone else's eyes" calculate and predict the mental states of other people (18). Namely, before doing anything, they imagine the reaction of others to their 
actions (19). This theory proposes that infants perceive others' mental states such as ideas, tendencies, wills, and excitements through their introspective experience (20). According to 'simulation theory', mirror neurons are considered to be very important; it means that these neurons first simulate the actions, and then the observers deduce the others' wills via their conceptual capacity (21). Baron-Cohen (22) clarifies the ontogeny of the theory of mind mechanisms according to the modularity hypothesis of the theory of mind. He believes that a man is equipped with an innate 'hard-wired' base for the acquisition of the theory of mind.

The human infant drew a distinction between a movement of animate and inanimate things around the six months of age. Joint attention faculty will be evolved in the infant about 12 months of age. Joint attention makes mention of the cognitive faculty that shape a triple representation contains the infant's own recognition, the agent's recognition (like babysitter), and the object which is in the infant's vision. About the age of 14-18 months, the human infant pays attention to the people and objects in its surrounding. At time, the infant begins to comprehend the mental states of others (23). In the 18-24 months of age the kid is capable of doing what Leslie (24) called 'decoupling', it means that $\mathrm{s} / \mathrm{he}$ is able to distinguish between reality and pretense. In other words, the infant can make difference between the physical and abstract events and begins to take part in 'pretend play'. The infants through participating in the pretend play can pretend to understand others which this process is the beginning of the formation of a mental faculty. Also, in the same age, the infants can identify themselves and others in a mirror (25). The ability to make a distinction between the children's own and others' beliefs just occur at the age of 3-4 years old in the normal children. Gradually, at the age 5 or 6 , the theory of mind appears in the normal children and they can understand that individuals can have beliefs about another person's beliefs. These beliefs can be right or wrong. At the same age, they can pass the false belief tasks (26).

The impaired theory of mind or mindblindness means facing trouble with having a viewpoint. It means that persons with an impaired theory of mind cannot understand their own and other's ideas. They cannot recognize other's mental states like their ideas, tendencies, and etc., and even they are not aware that how their behavior affect others (27). For the first time, Keeler (28) has observed in his research that congenitally blind children, like those with autism spectrum, suffered from social isolation and language disturbances. Other scholars by observing the certain features of autistic children like social isolation, inability to apply reflexive pronouns, repetitive gestures, using stereotyped statements in congenitally blinds have also confirmed the similarity between them $(29,30,31)$. According to some scientific studies on the theory of mind, the congenitally blind subjects, because of their defect, face with delay in the acquisition of social, cognitive, and linguistic abilities which they will overcome it by the school age. Due to the importance of these abilities in the growth of the theory of mind during infancy, the age of blind subjects to assessing the theory of mind through the cognitive tasks was considered to be more than that of sighted ones $(32,29,33)$.

To date, as far as this matter is concerned, there is not any study about the theory of mind in the Kurdish-Persian congenitally blind children based on the cognitive and linguistics tasks. Therefore, the main aim of the present research is to analyze the presence or absence of the theory of mind in the congenitally blind children and to specify the differences between the congenitally blind children and the sighted ones performance. Considering this goal, we are trying to answer the following questions: 1- how is the theory of mind faculty in congenitally blinds children 
compared to the sighted ones? 2- How is the function of the theory of mind regarding the age variable, in congenitally blinds children?

\section{Materials and methods}

This study is a descriptive-analytic study which aims at investigating the function of the theory of mind in the Kurdish-Persian congenitally blind children from the elementary level of Baghcheban school, the blind and deaf school, in Ilam province. Demographic characteristics of the participants were the same; in addition, all of them were right handed, mentally and cognitively intact, and in the moderate level of intelligence. Fortunately, due to the pre-pregnancy and pregnancy tests such as genetic screening, vaccination against rubella, diabetes and other prenatal cares, the numbers of congenitally blind infants have been decreased at birth that there were only 20 blind children in Ilam province in 2017 . Only 10 of them were eligible to participate in the experiments. Therefore, two groups of participants contain the experimental group (three age levels 6 to 9 years old (6-7, 7-8 and 8-9 years old)) and their equivalent control groups which abbreviated by "1", "2" and "3" were selected. The research instruments were three kinds of false belief cognitive tasks that were designed and localized to measure ToM development in the congenitally blind children. All three tasks were presented in a narrative form:

a. Sally and Ann task (Change of Location): This task was designed by Baron-Cohen and colleagues (34). In the present study, this task was localized by changing the characters names Sally and Ann to Sara and Ali and chocolate was used instead of marble. In the story scenario, there were two characters named Ali and Sara. Sara had a basket and Ali had a box in his hand. Sara put the chocolate in her basket and left the room. While she has gone, Ali took the chocolate out of the basket and put it in his box. Suddenly, Sara returned. Then, a false belief question (where will Sara seek for her chocolate when she returns?) was asked from the children. Afterwards, the memory questions (Where did she put the chocolate before she went out? and where is the chocolate now?) were asked. Memory test questions were required to measure the children's knowledge about the present position of the moved object and its previous position. If the child said that she will look for it in her basket, s/he took one point in the false belief task. To get a passing score (one point) in the memory questions, the child must correctly point to the current and previous position of the moved object. The 2 points were considered as a passing score in this task.

b. Story narration: The second tools for measuring ToM was from Peterson and Webb (33). This task contained a basket, a box, and a wallet full of coin money. All three objects were shown to the child and s/he was allowed to touch them. Before the child very eyes, the first examiner put the coin in the box and left the room. The second examiner drew a coin out of the box and put it inside the wallet. Then, the child was questioned, when the first examiner returns where will s/he search for the coin? If the child answered inside the box, s/he passed this task and otherwise, s/he failed. The memory questions were raised as follows: where the first examiner put the coin before s/he went out? And where's the coin now?

c. Content change task (change of content): This task was designed by McAllen \& Moore's task (35). This task was adopted by alternation of a milk container which was contained water with a warm teapot which was in fact filled with hot water. In this task, a teapot filled with hot water was given to the child and s/he was asked to touch it, in order to guess its contents. S/he by utilizing his/her prior experience assumes that it should contain tea. Afterwards, s/he was told to drink the teapot contents. After drinking, s/he realized that hot water was inside it. 
The child was presented the following false belief questions: 1-what they thought was inside the teapot? And 2-what would another person (who did not see the content of the teapot) think was inside the teapot? To pass these questions, s/he should say that tea had been there. The false belief questions were followed by this memory question: what is in the teapot now and before drinking its content, what would they think was inside it?

To get the acceptance score in all tasks, it is necessary to pass both the memory and false belief questions. It means that the passing score in each false belief task was "2" (for correct answer to both the memory and false belief tasks questions) and failing score was zero (either the questions of the memory and false belief tasks were answered incorrectly or only the questions of memory were answered incorrectly). Therefore, getting the total 6 scores was required to pass all three tasks.

\section{Statistical analysis}

In order to examine the statistical effect of the factors including visual state, age, and gender on false belief tasks, the parametric tests were applied which using it confirmed by one sample K-S. So, to assess the effect of visual state, the independent t-test along with Levenn test was employed. One-way Analysis of Variance (ANOVA) was applied for investigating the effect of age. To examine the simultaneous effect of visual state and age and also visual state and gender, the two-way ANOVA has been used. The SPSS software was applied to the statistical analyzes in which the examination of the statistical effects was evaluated in a level of significance $\alpha<0.05$.

\section{Results}

The normality test showed that the data for change of content, story narration and change of location had normal distribution $(\mathrm{P}>0.05)$. The visual state had statistically significant effect on the story narration $(\mathrm{P}<0.05)$, but did not have any statistically significant effect on change of content and change of location ( $\mathrm{P}>0.05)$. Comparing the mean time of response between sighted and blinded on the story narration indicated that the mean time of sighted individuals $(58.7 \mathrm{~s})$ was statistically more than blinded ones (34.1 s). Also, age did not have any statistically significant effect on three false tasks $(\mathrm{P}>0.05)$. In addition, visual state and age did not have any statistically simultaneous effect on all tasks $(\mathrm{P}>0.05)$. Figure 1 contains the $\mathrm{P}$ values along with the mean of responding time to the tasks based on the factors.

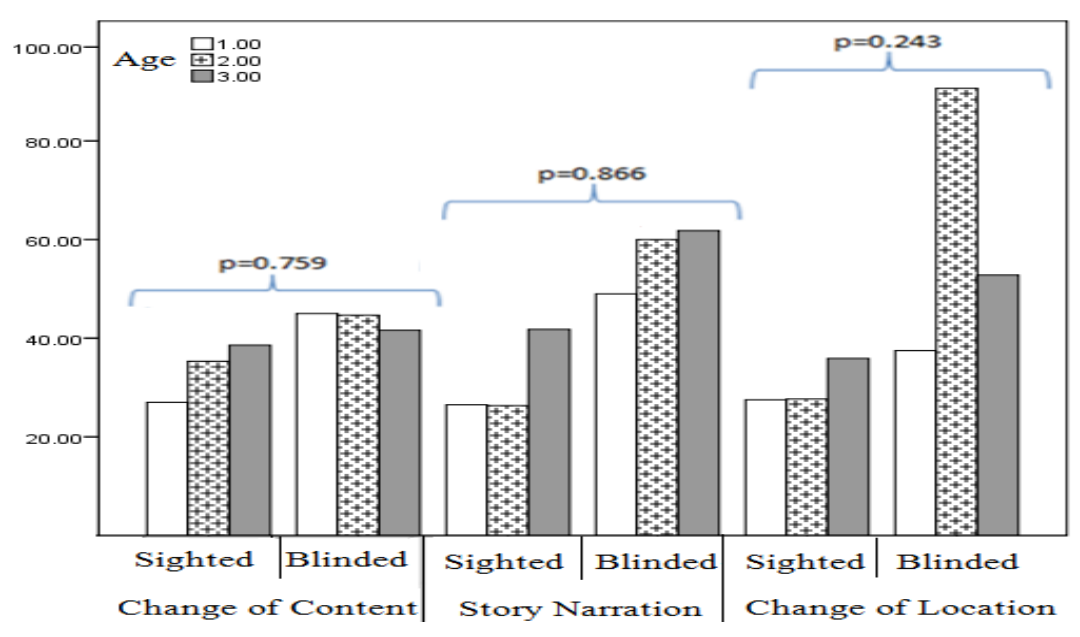

Figure 1. $P$ values based on the two-way ANOVA in the examination of the simultaneous effect of visual state and age on the false belief tasks. 


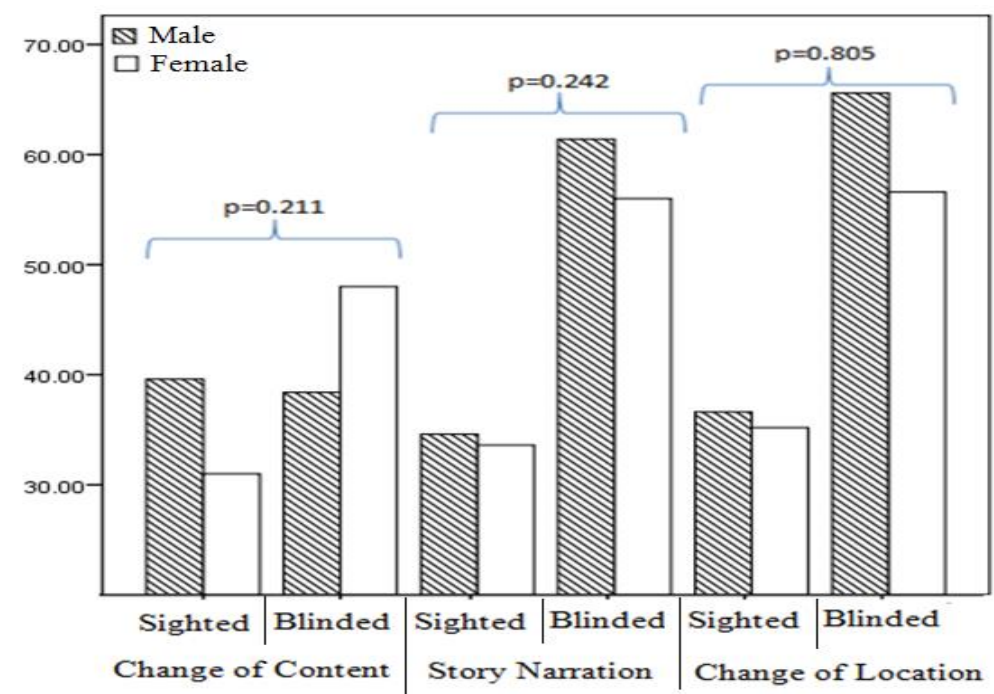

Figure 2. P-values based on the two-way ANOVA in the examination of the simultaneous effect of visual state and gender on false belief tasks.

\section{Discussion}

The performance of the congenitally blind children in three false belief tasks (change of content, change of location, and story narration) indicated that they have the developed theory of mind like the sighted children, but the blind children due to delay in accessing environmental data, achieve theory of mind knowledge at older ages than the sighted children. This result is in agreement with the researches of Baron-Cohen $(36,32)$ and Pe'rez-Pereira (37). Statistical analyzes showed that the type of false belief tasks had impact on the performance of individuals. Because, congenitally blind children had the same or even better performance than the sighted ones in change of location and change of content tasks. The only difference between two groups was in the story narration task which was statistically significant.

The correct answers of two groups to the memory questions indicated that there was no difference between them in terms of mental processing and cognitive functions. But, the only prominent feature of the blind children than the sighted ones was their high focus and strong sense of hearing. This outstanding ability of blind individuals is confirmed by the researches of Kahn \& Krubitzer (38), Sadato and Collegueas (39), and Roder and Collegueas (40). These researchers found out that the blind individuals'occipital lobe evolved for non-visual inputs. Therefore, the occipital lobe in the blind establishes a strong connection with auditory and tactile senses which it makes them very capable in these senses. Some reasons for spending more time by normal children are as follows: the sighted children understood the story after several times repeating, when some of them heard the story, they recount it in their own words, and etc.

The blind children performed the change of location task in less time than the sighted children. The better performance of blind children compared to those sighted ones was not statistically significant. Therefore, the blindness just had effect on the story narration task which it was statistically significant, while the blindness did not have any effect on the two other tasks like change of content, change of location. The same performance of the congenitally blind and sighted man and woman indicated that gender did not have any impact on the development of the theory of mind and their better performance. 


\section{Conclusion}

Among the three false belief tasks, the congenitally blind children had only poor performance in the story narration task. Because this task compared to other tasks was more dependent on the visual sense. So, it can be concluded that blindness leads to delay in the evolution of the theory of mind. It is recommended that congenitally blind children expose to

\section{References}

1. Birch A. Developmental psychology: From infancy to adulthood. $2^{\text {nd }}$ ed. London: MacMillan Press LTD; 1997. P. 185.

2. Premack DG, Woodruff G. Does the chimpanzee have a theory of mind? J Behav Brain Sci. 1978; 1(4):515-26.

3. Gallese V, Goldman A. Mirror neurons and the simulation theory of mindreading. Trends Cogn Sci. 1998;2(12):493-501.

4. Rizzolatti G, Craighero L. The mirrorneuron system. J Annu Rev Neurosci. 2004; 27:169-92.

5. Perrett DI, Harries MH, Bevan R, Thomas S, Benson PJ, Mistlin AJ, et al. Frameworks of analysis for the neural representation of animate objects and actions. J Exp Biol. 1989; 146:87-113.

6. Decety J, Chaminade T. The Neurophysiology of Imitation and Intersubjectivity. In: S. Huley, N. Chater (Eds), Perspectives on Imitation, Vol. 1. Mechanisms of Omitation and Imitator in Animals, MIT Press Cambridge: MA; 2005. P. 40-119.

7. Adolphs R. Conceptual challenges and directions for social neuroscience. Neuron. 2010; 65(6):752-67.

8. Frith U, Frith CD. Development and neurophysiology of mentalizing. Philos Trans R Soc Lond B Biol Sci. 2003; 358(1431):459-73.

9. Cross ES, Ramsey R, Liepelt R, Prinz $\mathrm{W}$, Hamilton AF. The shaping of further tactile and olfactory inputs during early infancy to fix this delay.

\section{Acknowledgement}

The financial assistance of the Cognitive Sciences and Technologies Council is greatly appreciated by the authors.

social perception by stimulus and knowledge cues to human animacy. Philos Trans R Soc Lond B Biol Sci. 2016;371(1686):20150075

10. Decety J, Lamm C. The role of the right temporoparietal junction in social traction: How low-level computational processes contribute to meta-cognition. Neuroscientist. 2007; 13(6):580-93.

11. Carruthers P, Smith PK. Theories of theories of mind. Cambridge: Cambridge University Press; 1996. P. 23.

12. Moore C. Theory of mind in infancy. Br J Dev Psychol. 2011; 14(9981):1940.

13. Flavell JH, Miller PH. Social cognition. In D. Kuhn \& R. Siegler (Eds.), Handbook of child psychology: cognition, perception, and language. Vol. 2. New York: Wiley; 1998. P. 851-887.

14. Miller PH. Theories of developmental psychology. $5^{\text {th }}$ ed. New York: Worth Publishers; 2009. P. 406-411.

15. Scholl BJ, Leslie AM. Modularity, development, and theory of mind. Mind Language 14(1):131-53.

16. Scholl BJ, Leslie AM. Minds, modules, and meta-analysis. Child Dev. 2001; 72(3):696-701.

17. Kazdin AE. Encyclopedia of psychology. Vol. 1-8. Washington DC: American Psychological Association; 2000. 
18. Flavell JH. Cognitive development: Children's knowledge about the mind. Annu Rev Psychol. 1999; 50:21-45.

19. Dennett DC. Reprint of Intentional systems in cognitive ethology: The Panglossian paradigm defended (to $\mathrm{p}$. 260). J Brain Behav Sci. 1987; 6(3):343-90.

20. Astington JW. The child's discovery of the mind. Cambridge, MA: Harvard University Press; 1993. P. 18-36.

21. Meltzoff A. Understanding the intentions of others: Re-enactment of intended acts by 18-month-old children. J Dev Psychol. 1995; 31(5):838-50.

22. Baron-Cohen S. The Eye Direction Detector (EDD) and the Shared Attention Mechanism (SAM). Two Cases for Evolutionary Psychology, In C. Moore \& PJ. Dunham (Eds.), Joint Attention: Its Origins and Role in Development. Hillsdale, NJ: Erlbaum. 1995; 41-59.

23. Saxe R, Carey S, Kanwisher N. Understanding other minds: Linking developmental psychology and functional neuroimaging. J Annu Rev Psychol. 2004; 55:87-124.

24. Leslie AM. Pretense and representation: The origins of theory of mind. J Psychol Rev. 1987; 94(4):41226.

25. Povinelli DJ. Reconstructing the evolution of mind. Am Psychol. 1993; 48(5):493-509.

26. Perner J, Wimmer H. John thinks that Mary thinks. Attribution of secondorder beliefs by 5-10 year old children. J Exp Child Psychol. 1985; 39:437-71.

27. Moore S. Asperger Syndrome and the Elementary School Experience. Shawnee Mission, KS: Autism Asperger Publishing Company; 2002. P.22.

28. Keeler WR. Autistic patterns and defective communication in blind children with retrolental fibroplasias. In P. H. Hoch and J. Zubin (Eds.), Psychopathology Commun. New
York: Grune and Stratton; 1958. P. 6483.

29. Fay WH, Schuler AL. Emerging language in autistic children. London: Edward Arnold; 1980.

30. Nagera H, Colonna AB. Aspects of the contribution of sight to ego and drive development: A comparison of the development of some blind and sighted children. Psychoanal Study Child. 1965; 20:267-87.

31. Wills DM. Early development in blind children. Psychoanal Study Child. 1979; 34:85-117.

32. Baron-Cohen S. Mind blindness. An essay on autism and theory of mind. Cambridge: MS, the M.I.T. press; 1995. P. 59-84.

33. Peterson CC, Peterson JL, Webb J. Factors influencing the development of a theory of mind in blind children. Br J Dev Psychol. 2000; 18(3):431-47.

34. Baron-Cohen S, leslie A, Frith U. Does the autistic child have a theory of mind? Cognition. 1985; 21(1):37-46.

35. McAlpine LM, Moore CL. The development of social understanding in children with visual impairments. J Visual Impair Blind. 1995; 89(4):34958.

36. Baron-Cohen S. How to build a baby that can read minds: Cognitive mechanisms in mindreading. Cahiers de Psychol Cogn. 1994; 13(5):513-52.

37. Pérez-Pereira M, Conti-Ramsden G. Do blind children show autistic features? In: Pring L, editor. Autism and blindness. London: Whurr Publishers. 2005; 99-127.

38. Kahn DM, Krubitzer L. Massive crossmodal cortical plasticity and the emergence of a new cortical area in developmentally blind mammals. Proc Natl Acad Sci U S A. 2002; 99(17): 11429-34.

39. Sadato N, Pascual-Leone A, Grafman J, Ibañez V, Deiber MP, Dold G, et al. Activation of the primary visual cortex by Braille reading in blind subjects. Nature. 1996; 380(6574):526-8. 
40. Röder B, Rösler F, Neville HJ. Event-

blind and sighted people. related potentials during auditory Neuropsychologia. 2000; 38(11):1482language processing in congenitally 502. 